\title{
LITERATURA Y EXILIO:
}

EL CASO DE DOS ESCRITORES CHILENOS* *

Alicia Arroyo *

La presente investigación pretende indagar en la relación que existe entre agencia y estructura social en el caso concreto de la experiencia del exilio y la creación literaria. El impacto de las estructuras sociales y de los procesos políticos en la vida de los individuos parece ser más evidente en períodos de cambio violento. Así, los exiliados experimentaron en su país una etapa de apertura y, en cierta manera, una revolución, que tenía por objeto transformar la estructura social tradicional de Chile, esta experiencia fue interrumpida por el golpe militar y el establecimiento de una dictadura.

Con el objeto de comprender mejor la transcendencia que pude tener el exilio en la vida de las personas se ha utilizado la idea de Giddens de la relación entre actor y estructuras sociales, estás, por un lado, imponen sus limitaciones al individuo determinando sus condiciones de vida, pero simultáneamente proporcionan una oportunidad o un margen de acción.

Los exiliados son consecuencia del fracaso político y de la imposición de un sistema autoritario y se ven obligados a abandonar su país o arriesgarse a perder la vida. Es una tragedia que afecta a gran parte de la humanidad. Sin embargo, estas personas no son víctimas pasivas, llegan a un país extraño con todo un bagaje cultural y político ajeno al nuevo contexto donde deben desarrollar o continuar sus vidas, esta situación implica una redefinición de sí mismos y de su relación con el mundo. En este proceso los refugiados deben aprender a superar y a vivir las

\footnotetext{
* Profesora de la Facultad de CC. Jurídicas y Sociales de la Universidad Rey Juan Carlos

** Comunicación presentada y leída por su autora en el IV Encuentro Regional de Sociólogos y Politólogos celebrado en Almagro (Ciudad Real), los días 22 y 23 de octubre de 1999.
} 
limitaciones y ventajas que le son impuestas por el exilio. En este trabajo, la atención se centra fundamentalmente en la creación literaria de dos escritores chilenos, cómo ha sido transformada por estos procesos sociales y políticos. Para conseguir este objetivo, primero consideraremos brevemente las condiciones que abocaron al exilio, así como la situación de la comunidad de refugiados chilenos en Gran Bretaña. En segundo lugar, estudiaremos la trayectoria vital de estos escritores y, posteriormente, se realizará un análisis de algunos de sus textos, para demostrar cómo el objeto artístico esta íntimamente ligado a las circunstancias históricas y sociales de los artistas. Los grupos sociales con los que se identifican, sus valores y emociones están mediatizados por la experiencia del exilio.

\section{EL MODELO CHILENO HACIA EL SOCIALISMO Y EL GOLPE DE ESTADO}

La experiencia chilena tuvo una repercusión internacional muy importante ya que intentaba transformar la sociedad de una forma pacífica y democrática. La Unidad Popular ganó las elecciones en 1970 y en los tres años de gobierno no consiguieron desmantelar las estructuras de poder tradicionales. Sin embargo, lo más novedoso de este período fue que, por primera vez, los ciudadanos de a pie podían participar activamente en este proceso de cambio, produciéndose un renacimiento cultural y político, caracterizado por una notable participación y concienciación de la ciudadanía.

En el tercer año de gobierno de la UP, Chile se había convertido en una sociedad polarizada, formada por grupos antagónicos, por un lado, los trabajadores y campesinos presionando para conseguir cambios más significativos y, por otro, las clases dominantes tradicionales que veían amenazado su status quo. Así, el golpe de estado tiene lugar en el contexto de una nación dividida, con la intervención de grupos de extrema derecha y de una gran parte de las Fuerzas Armadas que el Gobierno fue incapaz de controlar y que culminó en la imposición de una dictadura militar.

Resulta irónico e ilustrativo que precisamente en el período inmediato al golpe, uno de los escritores, Alfredo Cordal, estaba ultimando una obra de teatro «La mala suerte del conejo» que trataba en tono satírico la posibilidad de un golpe de estado, el Golpe tuvo lugar cuando realizaban los últimos ensayos y tuvieron que suspender la obra.

Después del Golpe se produjo un cambio dramático en la sociedad chilena, los militares tomaron el control de todas las esferas de la vida cotidiana, incluidos la Universidad y los Medios de Comunicación. El nuevo régimen militar llevó a cabo una actuación sistemática de brutalidad, tortura y asesinatos: «Murieron miles de personas, quizás 30.000 en los primeros seis meses y durante ese período llego a haber 80.000 prisioneros políticos» (Third World Quarterly, p. 149).

Así pues, el Golpe del 11 de Septiembre de 1973 significó una gran derrota 
para todos los partidos de izquierda. Los trabajadores y campesinos no sólo perdieron los derechos adquiridos a lo largo de la historia, sino también la posibilidad de una revolución socialista que nunca había estado tan cercana. En el ámbito cultural, la gran actividad que se estaba desarrollando durante el Gobierno de la Unidad Popular fue brutalmente silenciada.

\section{EL EXODO}

La huida a otros países se debe entender desde el contexto de terror y represión que supuso la dictadura, forzando a muchas personas a abandonar su país o perder la vida. No existen datos exactos del número de refugiados, pero el Alto Comisionado de la ONU tenía un registro de 30.000 , aunque el número podría ser mayor.

El número de refugiados que llegaron al Reino Unido antes de 1980 estaba en torno a los 4.600, a partir de esa fecha, con el Gobierno de Margaret Thatcher, aumentan las dificultades para conseguir asilo político. La gran mayoría apoyaban al Gobierno de la Unidad Popular, con un alto porcentaje de intelectuales y académicos, su militancia era muy variada. En el período que se realizó esta investigación (1989), todavía era peligroso volver a Chile, de hecho, algunos retornados fueron asesinados.

\section{LAS CONDICIONES SOCIOPOLÍTICAS DEL EXILIO}

La llegada de los chilenos al Reino Unido coincide con un período de recesión económica, además los ubicaron en zonas con un paro muy alto y viviendas muy deterioradas. Muchos chilenos, incluidos los que tenían estudios superiores, no podían encontrar trabajo y se enfrentaron a diversas dificultades para su integración social en el país que les había acogido. Uno de los principales problemas era que la mayoría no hablaba inglés. Una vez instalados, experimentaron un fuerte choque cultural, debido a la diferencia de costumbres y de idioma, que dio lugar a toda una serie de conflictos.

Las primeras sensaciones que produce el exilio son de miedo, incertidumbre e, incluso, paranoia. La capacidad para enfrentarse a estos problemas estaba, en cierto modo, determinada por la clase social: las clases medias altas y profesionales liberales ya habían estado en Europa y muchos hablaban inglés, mientras que para los trabajadores suponía un reto mucho mayor. Uno de los principales dilemas o conflictos al cual debían enfrentarse era el cambio de ser ciudadanos activos e involucrados en el proceso de cambio social, a convertirse en ciudadanos pasivos con unos derechos muy limitados. Otra de las consecuencias del exilio fue el cambio en la movilidad social, de tal forma que las clases medias experimentaron una movilidad social descendente, su nivel de vida bajó considerablemente, en comparación con Chile; en contraste, para muchos trabajadores su nivel de vida aumentó, respecto a su situación en Chile. En general, en mayor o menor medida, 
todos experimentaron frustraciones, aislamiento y dificultades para encontrar trabajo, sus circunstancias eran desfavorables, a todos los niveles, similar a la de cualquier otra minoría étnica.

La experiencia del exilio, como cualquier otro proceso histórico, no es experimentada de la misma forma por todos los individuos que la viven, con Sartre dice: «la misma realidad objetiva se vive de distinta manera, según la edad, clase social y situaciones personales». El exilio supone convertirse en objetos de la historia, en lugar de sujetos de la misma. Utilizando el concepto de proyecto vital de Sartre, podemos comprender mejor la experiencia del exilio, en Chile existía un proyecto colectivo que fue violentamente abortado y posteriormente anulado por el éxodo, los refugiados chilenos tuvieron que aprender a vivir en una cultura que les era ajena, a redefinirse a sí mismos e intentar continuar sus proyectos interrumpidos.

El exilio es un castigo, los individuos son despojados de su biografía y de su historia colectiva, separados de su marco de referencia natural: la sociedad donde han nacido y vivido. Los refugiados pierden su nacionalidad, pueden visitar todos los países del mundo, menos aquel del que provienen, una ironía; esta situación les lleva a vivir en dos mundos aparte: el país que les acoge y el país que tuvieron que abandonar, fuente de sueños, memorias y frustraciones. En el momento de realización de esta investigación habían transcurrido unos 15 ó 20 años de exilio, muchos han aprendido inglés y se han adaptado a Inglaterra, continuando sus proyectos interrumpidos y manteniendo, en la medida de lo posible, su cultura e identidad. El fenómeno del exilio se debe entender en sentido dinámico y no estático, la experiencia cambia a lo largo de los años, pero siempre mediatiza la biografía del individuo y su relación con las estructuras sociales donde se encuentra ubicado.

\section{LAS CONDICIONES SOCIO-ECONÓMICAS DE LOS AUTORES}

En esta investigación se considera la producción artística como un proceso, donde intervienen de forma crucial factores sociales y económicos que, en mayor o menor grado, mediatizan la creación del producto y su difusión. Así, en el caso de los escritores es imprescindible tener cierto conocimiento de las tradiciones literarias, tener acceso a editoriales y publicaciones, y sus posibilidades dependerán, en gran medida, de la situación del mercado, de la publicidad y de los críticos literarios.

El estudio de la obra de estos autores no se puede abordar sin considerar que son refugiados: fueron censurados y perseguidos en su país y cuando llegaron a Inglaterra tuvieron que aprender inglés, redefinir su situación y buscar una nueva audiencia, así como caminos para acceder a la publicación de sus obras. Ambos pertenecían a la clase media-alta, el exilio significó un descenso en la estructura social y han tenido más dificultades para sobrevivir que en Chile, realizando todo tipo de trabajos, generalmente con salarios muy bajos y poco cualificados.

Ninguno de ellos puede vivir de su producción artística, deben realizar 
otras labores para sobrevivir, pero su verdadero trabajo consiste en escribir, esta situación de inestabilidad y precariedad económica limita sus posibilidades de creación artística. Sin embargo, a pesar de las dificultades, ambos han encontrado caminos para poder publicar y difundir su obra, bien a través de subvenciones, o creando, junto con otros escritores latinoamericanos, una pequeña editorial.

Así pues, a pesar de las limitaciones económicas que se imponen, en cuanto a la posibilidad y condiciones materiales de producción, esto no parece afectar ni al estilo, ni al contenido de la obra.

\section{LITERATURA E IDEOLOGÍA: EL COMPROMISO POLÍTICO}

En el estudio de la influencia del compromiso político en la creación literaria, se analizan dos aspectos: por un lado, la relación entre escritores y partidos políticos y, por otro, escritor-audiencia.

El papel del compromiso político del escritor adquiere protagonismo en los debates literarios europeos a partir de la revolución rusa y tiene su mayor auge durante el período de entre-guerras, coincidiendo con la expansión del fascismo. En la actualidad, mientras que en Europa no parece inquietar demasiado a los escritores, en América Latina, debido a las numerosas dictaduras y a los conflictos sociales, sigue siendo un debate vigente. En este trabajo nos ceñimos exclusivamente al ámbito de la izquierda y del socialismo, ya que ambos autores militaban en partidos políticos que apoyaban el Gobierno de la Unidad Popular, y el motivo de su exilio ha sido sus creencias y valores socialistas.

La relación entre los escritores y los partidos políticos puede ser indicativa de la influencia del compromiso político. Según la clasificación establecida por G. Steiner (J. Wolf, p. 87), existen dos corriente: los ortodoxos y los neo-marxistas. Los primeros son aquellos que juzgan la calidad de la literatura en función de los criterios y doctrinas del partido, así, Lenin consideraba que la buena literatura era la que se inspiraba en los principios dictados por el partido. El ejemplo paradigmático de esta corriente sería el realismo social, que se convirtió en la norma literaria en las sociedades comunistas. La otra corriente cuenta con críticos como Engels, Lukas y Trotsky, para ellos el enfoque ortodoxo tenía una concepción demasiado limitada del arte, la literatura buena es aquella que presenta una comprensión de la realidad social, transmitida a través de la ficción, sin que el autor imponga su compromiso político desde fuera, la crítica y el análisis social deben emerger del propio texto (Golf, 1987)

Por otro lado, la Escuela de Francfort que criticaba la literatura oficial y ortodoxa porque carecía de calidad al convertirse en mera propaganda. El carácter revolucionario del escritor debería manifestarse en la innovación de la propia literatura, como la obra de Bertolt Brecht.

Los dos autores pertenecían a distintos partidos políticos, sin embargo, a pesar de su fuerte compromiso político y su ideología socialista, abiertamente 
manifestada, no se pueden encuadrar en la corriente ortodoxa, sino, más bien, encajarían en la corriente neo-marxista, ya que, por un lado, exponen la realidad social de su país y del exilio, pero sin descuidar la calidad literaria. El compromiso político esta implícito en su obra, al contrario que en su discurso político, pese a que en el exilio ambos abandonaron sus respectivos partidos. Los motivos que les llevaron a abandonar la militancia fueron, entre otros, la reducción del espacio político, el margen de acción, y los problemas de sectarismo y fragmentación en los partidos en el exilio.

Para Roberto Rivera no tenía sentido militar en el exilio. Y Alfredo Cordal nos dice:

«Cuando estaba en Chile militaba en el Partido Socialista, había mucha libertad y yo estaba muy comprometido, el partido nunca supuso un obstáculo para mi creación, al contrario, aprendí mucho... Cuando llegué al exilio perdí el contacto con mis camaradas y me alejé de la crisis de los partidos, necesitaba tiempo para reflexionar sobre lo que había ocurrido».

Sin embargo, ambos siguen comprometidos con los valores socialistas, pero la experiencia del exilio les ha hecho ser más críticos con respecto a los partidos y ala forma en que llevaban a cabo sus programas, en particular, en cuanto a las actitudes hacia los indígenas y el medio ambiente. En ambos autores se puede diferenciar claramente el discurso político de su creación literaria que, aunque comprometida, no es mera doctrina. Los valores y la ideología de los escritores se manifiestan mediante las convenciones estéticas «las formas de producción artística disponibles juegan un papel activo en la construcción del objeto artístico, los propios autores se han formado socialmente mediante las convenciones literarias y culturales de estilo, lenguaje, género y vocabulario estético» (J. Wolf, 1981). Así, Alfredo Cordal, ha estudiado las religiones y mitología indígenas y, desde su punto de vista, el cristianismo, a excepción de la Teología de la Liberación, supone una forma de dominación. Para este autor el problema del ser humano es esencialmente político. La experiencia del exilio ha hecho que ambos autores rescaten y descubran, desde una nueva perspectiva, la cultura indígena, su capacidad de resistencia y de identidad frente a la imagen romántica o exótica. Su creación literaria esta mediatizada por estas nuevas percepciones de la realidad.

Otro aspecto fundamental para comprender el compromiso del escritor, es su relación con las audiencias, que será presentado desde el punto de vista de los autores. Para Roberto Rivera «el poeta es la persona capaz de percibir y recoger los sentimientos de los demás, aunque siempre se escriba desde el punto de vista del escritor, el poeta debe estar abierto a los otros y aprender de ellos, transmitiendo sus valores y sentimientos». Para Alfredo Cordal «el papel del poeta en el exilio consiste en dar testimonio de su cultura, del sufrimiento y de la opresión de su pueblo, mediante la poesía y el teatro».

El exilio ha tenido un fuerte impacto en la relación entre autor y audiencia: en primer lugar, han sido censurados en su propio país, han perdido gran parte de lo 
que sería su «audiencia natural»; en segundo lugar, les acoge un país donde se habla otro idioma, el público británico es de difícil acceso para estos autores; y, en tercer lugar, la comunidad de refugiados chilenos es muy reducida. En este contexto de reducción radical de la audiencia se han visto obligados, no sólo a aprender inglés, sino también a buscar canales apropiados de comunicación, tarea ardua.

Ambos autores se consideran parte de la comunidad de chilenos, pero también es importante para ellos tener contacto con el público británico, así, en los eventos sociales o fiestas, leen sus poemas en inglés y en español. En este sentido, se sienten integrados en el medio donde viven. Alfredo Cordal apunta: «Me siento integrado, ha visto la necesidad de dar testimonio de mi cultura, es una integración en el medio británico, pero sin perder tu propia cultura, no es una absorción».

El compromiso de político de los autores ha sido transformado por la experiencia y los años de exilio, probablemente, los cambios no sean tanto en sus principios, como en su visión del mundo y de sus objetivos, así como en la relación con la audiencia. Estos autores tienen una conciencia política que no han perdido, a pesar de los años: se sienten identificados con los campesinos, los trabajadores y los pobres. Su compromiso se manifiesta en los textos, a través de la transmisión de sus valores, cultura y problemática.

\section{LA CREACIÓN LITERARIA}

El artista y su trabajo están ubicados en la historia, su biografía y experiencia personal influyen en la forma y contenido de su trabajo. En este apartado analizamos el contenido de los poemas. Existe un debate en cuanto a los distintos enfoques teóricos que nos permiten analizar un texto literario, entre los más representativos se encuentran el formalismo y el estructuralismo. Los primeros consideran el texto como el único elemento relevante, por lo tanto su análisis se realiza en función de los distintos recursos literarios, estructuras narrativas, etc.; los segundos se centran en la forma y estilo del texto. La contribución más importante de este enfoque a la sociología de la literatura, consiste en el énfasis e importancia que otorga al texto. Sin embargo, una excesiva concentración en el texto puede resultar en un análisis que ignore su dimensión histórica. Por el contrario, los estructuralistas se han empleado tan a fondo en tratar las condiciones objetivas y materiales de producción y la situación del autor en la sociedad, que parecen olvidar el texto en el proceso de análisis.

Cuando se analiza un texto debemos ser conscientes que la literatura no refleja la realidad social como si fuera un espejo, no los factores económicos o las ideologías, sino que, en palabras de Singewood: «La literatura imaginativa es una reconstrucción del mundo, percibido desde un punto de vista particular, aunque el autor sea consciente de la tradición literaria, el interés de la sociología de la literatura se debería centrar en el universo ficticio, producto de la reelaboración inconsciente de la experiencia y de los valores del autor». 
Esta cuestión nos lleva a la importancia que puede tener el papel del autor en el análisis del texto, es decir, hasta que punto la biografía es importante para comprender el significado del texto. Sartre ha señalado la importancia de este aspecto en su método «progresivo-regresivo», los aspectos existenciales psicoanalíticos del autor son significativos para analizar el texto, ya que estudiar la ideología dominante que pueda expresar el texto y las circunstancias histórico-sociales del autor no son suficientes. algunos críticos literarios marxistas conciben a los escritores como meros portadores de ideología. El texto literario es un objeto único, resultado de la posición específica del autor en la sociedad, pero también de su biografía.

Ambos autores tienen la misma ideología y han experimentado el mismo proceso histórico e, incluso, pertenecen a la misma generación, sin embargo, la forma en la que escriben, aún tratándose del mismo tema, es totalmente distinta. Estas diferencias de estilo apuntan a la importancia de la biografía de los autores, aunque esta sea colectiva y socialmente construida. Como J. Wolf sugiere, el concepto de autor estático y uniforme ha dejado de tener sentido, más bien, deberíamos entenderlo, mediatizado por el lenguaje, la ideología y las relaciones sociales, entonces, cobra una relevancia central, tanto para la compresión del texto, como de la literatura.

\section{ROBERTO RIVERA REYES}

El objetivo de este autor es concienciar al publico sobre temas que considera esenciales, para él escribir es un acto colectivo: «Yo he sido el que he escrito el libro, pero las ideas, creencias y sentimientos sobre los que escribo, son colectivos». El escritor se identifica y siente que forma parte de Chile, a pesar de no estar allí.

El exilio es un tema recurrente en sus poemas, aunque, con distintas imágenes y enfoques. Los primeros poemas están marcados por el golpe y la lucha del pueblo chileno que presenta de forma heroica, a pesar de los continuos fracasos, la muerte y la represión. La esperanza y fe en el futuro contrastan con la cruel realidad que se puede apreciar en sus versos. También trata del inicio del exilio el conjunto de poemas «Apología Asesinada», se refiere a este período y transmite una profunda tristeza, soledad y nostalgia, así como una pérdida del sentido de la vida; las experiencias que vivió fueron tan traumáticas que, aún cuando intenta escribir sobre otras cuestiones, siempre aparecen, «la presencia del exilio está siempre ahí, es como un fantasma». En uno de sus poemas, «Sueños Dementes», expresa la confusión creada por el exilio, utilizando la metáfora de un barco abandonado a la deriva, en el mar abierto, se ha perdido el contacto con la tierra, se abandonan las raíces: «Cuando estaba en la embajada de Colombia y pedía silo, podía ser como la lotería, me podía tocar cualquier país, el problema es que no sabes dónde vas a ir, cómo va a ser tu futuro, no puedes hacer ningún plan». La vida se vuelve absurda, pierde sentido y significado, es como una pesadilla en la que huyes de la muerte, pero la muerte está presente. En el poema, la muerte esta personificada en los desaparecidos, los cuerpos muertos que rodean al barco. Otra expresión o manifestación 
del exilio es la nostalgia e idealización del país perdido, la infancia, las memorias, los recuerdos, el campo y los paisajes que quedan plasmados en su poema «Orígenes».

Roberto Rivera tiene una visión crítica del hombre moderno, le considera alienado respecto a la Naturaleza, inmerso en una carrera de destrucción y consumo. En su obra nos presenta un modelo alternativo del ser humano, basado en el rescate de los valores culturales de los indígenas, su respeto y armonía con la naturaleza. Precisamente la experiencia del exilio le ha hecho reflexionar sobre estas cuestiones, su poesía se inspira en la naturaleza, especialmente en los bosques y árboles y este amor por la naturaleza le ha llevado a concienciarse sobre los problemas que la amenazan. Así, en su poema «Los Molinos de Don Quijote», nos presenta un Quijote que recorre un paraje asolado por la bomba nuclear. En el análisis de su obra se puede observar una evolución temática del exilio y de Chile, a otros temas como son la preocupación de la amenaza nuclear o la ecología.

\section{Los Molinos de Don Quijote}

Por entre laberintos de avisos luminosos

cadavéricamente galopa el caballero de La Mancha,

ornamento de sus armas, una máscara de gases

y enmohecida armadura sobre el cuerpo

que a duras penas resiste Rocinante.

En cada ciudad enfrenta a monstruosos bloques de cemento, habla de paz a los lobos en una base coheteril, discute con gigantes hélices pegadas al suelo contaminado cual calavera de vaca clavada sobre una estaca en el desierto.

Vuelan hojas de un periódico en desuso por las calles sucias como retobos de existencias arrastradas por el viento $y$ en un esfuerzo sublime de concentración quisiese parar el tiro que rompe la barrera del sonido en loca carrera con el tiempo.

Sus poemas están recogidos en su único libro publicado «Cazadores del Alba y Otros Poemas», los cazadores del alba representan al hombre moderno, los militares que reprimen, lo que mataron a los indios, los que contaminan el planeta. Para Roberto todos somos, en cierta manera, cazadores del alba, puesto que no podemos escaparnos de la sociedad en que vivimos; la sociedad de consumo es algo que siente presente en todos los momentos de la vida cotidiana, representa la filosofía de obtener el máximo beneficio a corto plazo, sin pensar en las generaciones futuras. En contraste, el alba simboliza libertad, fuego, el planeta, los cazadores son los destructores del alba y del planeta, así como los mapuches representan la esperanza y la armonía con la naturaleza. 


\section{ALFREDO CORDAL}

Para este autor, escribir es una manera de dar testimonio de su cultura ya que el exilio es una condición de privilegio, comparado con la gente que esta en Chile. Se siente obligado a expresar los problemas, no sólo de Chile, sino de todo el continente latinoamericano. La experiencia del exilio le ha hecho reflexionar sobre el cristianismo: desde su punto de vista, esta religión, en sus orígenes era liberadora, pero, a lo largo del tiempo, se convirtió en una religión dominadora; en la actualidad, con la Teología de la Liberación, el cristianismo tiene un nuevo sentido, apoyando a los pobres y oprimidos. «El Juicio Final» es uno de los mayores exponentes de estas ideas. La obra fue representada por actores británicos y tuvo muy buenas críticas en la prensa. Esta obra trata de un cura que proviene de una rica familia y vive con los pobres, el sacerdote rechaza a su familia por todo lo que representan: los rasgos típicos de la élite latinoamericana. El sacerdote es arrestado y torturado. En el transcurso de la tortura sufre una serie de alucinaciones, entre ellas mantiene un dialogo con su padre y su madre, en el dialogo entre padres e hijo, Alfredo Cordal manifiesta la ideología decadente y la corrupción de estas clases. Otro conjunto de alucinaciones le sirven para introducir la cultura precolombina, los guerreros aztecas, el tigre y el águila se le aparecen también al protagonista, todo ello mediante flash backs. Esta historia denuncia la situación de muchos países latinoamericanos y la importancia de la Teología de la Liberación.

La experiencia del exilio le ha servido para reflexionar sobre la importancia de las culturas precolombinas y el mestizaje, así un viaje que realizó a México fue una experiencia impactante, este país es el paradigma de las tres culturas que él encuentra en sí mismo y en su pueblo: precolombina, colonial y moderna; además, piensa que la distancia le ha ayudado a profundizar en la nostalgia y a visualizar e integrar la historia de Chile en el contexto del Continente y del Tercer Mundo.

Sus obras de teatro son ricas en símbolos, sueños y ritos, es un escritor muy innovador. Mediante diferentes recursos literarios nos cuenta la historia de su continente, así «El Juicio Final» es una obra que puede ser valida para cualquier país de América Latina. En otra de sus obras, «El Espejo de Humo», analiza la lucha de poder que tienen lugar entre las distintas clases sociales y culturas. En esta obra nos relata la historia de La Malinche y Cortes, paralelamente ocurre otra historia de una joven prostituta y un magnate americano del petróleo, sugiriéndonos que la historia se repite.

La Malinche es una mujer legendaria, una princesa noble que nació en días terribles, según marcaba el calendario azteca, su madre la vendió como esclava, pertenecía a ala tribu de Los Toltecas, sometidos al Imperio Azteca. La Malinche creía que los españoles habían venido a salvar a su gente, y, aún más, después de la profecía de Quezatcoatl. Se alió con los españoles traicionando a los indios, cuando ve la masacre se pregunta para qué ha servido, puesto que se ha liberado de los aztecas para ser sometida a los españoles. La obra de Alfredo Cordal no es tanto un 
relato histórico, como una manifestación de la sed de poder y dominación, expresado mediante un conjunto de símbolos, rituales y sueños en flash backs. El espejo es un elemento fundamental en la obra, mirándose en él, tanto La Malinche como Cortes, mantienen una serie de diálogos internos y viajan a través del tiempo. También los personajes se mueven desde el pasado al presente y al futuro, y de México a España, y viceversa. La obra relata como Cortes acabó pobre y olvidado, señalando lo absurdo de su misión en nombre del Emperador y de Dios.

Su poesía trata de los mismos temas. Alfredo Cordal prefiere difundir su obra «en vivo y en directo», primero como forma de entendimiento, para que los espectadores puedan divertirse y olvidarse de los problemas cotidianos, y en segundo lugar, para hacer pensar al público, y cuando la audiencia es latinoamericana, su objetivo es que no pierdan contacto con su propia cultura. Para él, escribir es una forma de resistencia, no sólo hacia la dictadura, sino también, al tiempo, «escribir me da fe, es la única manera de seguir adelante».

\section{Pueblo Nuestro}

Pueblo nuestro que estas en prisión

conocida sea tu causa.

Venga a nos tu sueño,

hágase tu libertad,

aqui en la tierra como en las estrellas.

Danos el pan de cada día como el futuro que anhelas.

Y perdónanos nuestra libertad

así como nosotros no olvidamos

que has preferido la prisión al exilio.

$Y$ no nos dejes caer en la desesperanza,

mas libranos de todo mal

que nos divida y detenga en la lucha constante.

\section{CONCLUSIÓN}

El artista también forma parte de la sociedad y como tal esta condicionado por las estructuras y procesos sociales, así el papel del autor se comprende mejor como histórico-concreto, tanto el proceso de producción artística, como su resultado final estarán en función de la ubicación social del artista. Las condiciones económicas y materiales de los autores determinan sus posibilidades y oportunidades: el exilio ha supuesto un deterioro de su nivel de vida comparado con Chile, y el tener que realizar otros trabajos ajenos a la creación literaria. El exilio es una condición dinámica, ha supuesto una serie de limitaciones, pero también otras oportunidades, ha significado reflexionar y reanudar un proyecto vital interrumpido, el cuestionarse muchas cosas que anteriormente las daban por sentadas. 
Los autores han aprendido a vivir en dos mundos aparte, su vida cotidiana en Inglaterra y el mundo de las memorias y sueños de Chile, viven esta dualidad de forma positiva (se sienten privilegiados en comparación con los que se quedaron en Chile), ya que por muy trágico que sea el exilio, ellos han tenido tiempo para reflexionar y desarrollar su trabajo.

Los escritores forman parte de un grupo social, de una cultura y de una ideología y esto influye en la creación literaria, ambos tienen una visión del mundo similar, pero distintas maneras de expresarla, producto, en gran parte, de sus distintas biografías, sin embargo ambos coinciden en la necesidad de «un hombre nuevo». Son muy conscientes de la importancia de los procesos históricos en nuestras vidas y lo perciben como una lucha continua cuyo propósito es la liberalización. Tanto el exilio, como esta perspectiva del mundo, mediatiza sus poemas, su obra literaria es específica, ligada a un momento histórico concreto y a la experiencia del autor, como ha vivido dicho proceso, por ejemplo, ambos autores han recuperado, de distinta manera, la cultura indígena.

En esta investigación espero haber demostrado que el artista y su trabajo están condicionados, en mayor o menor medida, por factores económicos y sociales. El individuo está determinado por los procesos sociales que tienen lugar en la sociedad de la que forma parte y esto queda patente en el caso de la imposición de una dictadura militar y del exilio. El artista como individuo libre de ataduras y de actuar a su antojo, no es más que un mito, así hemos visto como la trayectoria vital de los autores se alteró de forma dramática debido a los cambios en la estructura de poder en Chile, pasando de ser protagonistas activos de un renacimiento cultural, a ser perseguidos y forzados al éxodo. También la experiencia de estos autores nos demuestra que casi siempre existe cierto margen de acción y ellos han sabido buscar las oportunidades para seguir desarrollando su creación literaria, a pesar de las dificultades.

\section{METODOLOGÍA}

El marco teórico se basa fundamentalmente en ideas marxistas y también en la sociología de la literatura de Janet Wolf, Singewood y, sobre todo, J. P. Sartre. Los principales conceptos teóricos utilizados para realizar esta investigación son los siguientes:

- La importancia de considerar al ser humano como histórico-específico, por eso hemos considerado necesario hacer una breve introducción histórica para situar a los autores en el contexto general donde se desarrollan sus vidas, primero en Chile y posteriormente en Gran Bretaña.

- La importancia de la clase social para comprender la historia y la posición del actor en las estructuras sociales, cómo esta puede condicionar sus oportunidades.

- Las estructuras sociales como determinantes y al mismo tiempo permitiendo cierto margen de acción, hemos seguido la idea de Anthony Giddens. 
- Considerar la producción artística como un proceso social, mediatizado por las estructuras sociales donde se encuentra el artista, así como sus valores e ideología.

- El compromiso político tiene un papel clave para comprender la condición de exiliados de los escritores y su obra, aunque no se puede reducir a mera ideología.

- El método progresivo-regresivo de Sartre, así como su concepto del proyecto vital, también ha sido utilizado para comprender mejor el fenómeno del exilio.

La técnica de investigación utilizada ha sido historias de vida, mediante entrevistas en profundidad, no estructuradas, que nos han permitido obtener mucha más información de la que luego se ha utilizado. Las entrevistas transcurrieron en un ambiente de confianza y sinceridad, con algunos momentos muy dramáticos. Se realizaron varias sesiones con cada uno de los autores. 